\title{
POTENSI LAHAN PENGEMBANGAN PERTANIAN HORTIKULTURA BUAH NANAS UNTUK PENGEMBANGAN WILAYAH DI KABUPATEN SUBANG
}

\author{
Land Potency for Development of Pineapple Horticultural Fruit for Regional \\ Development in Subang Regency
}

Meyliana Lisanti ${ }^{1}$, Widiatmaka ${ }^{2}$ dan Sahara ${ }^{3}$

Diterima: 30 November $2017 \quad$ Disetujui: 17 Agustus 2018

\begin{abstract}
Abstrak: Kabupaten Subang memilki sektor andalan di bidang pertanian yaitu terdapat pada jenis hortikultura buah nanas. Menurut Perda RTRW Kabupaten Subang Tahun 2011 - 2031 potensi pertanian dalam peluang peningkatan kemampuan pembiayaan pembangunan wilayah di Kabupaten Subang yaitu berpotensi pada buah nanas. Tujuan penelitian ini adalah untuk : (1) mendeliniasi lahan tersedia untuk buah nanas, (2) mengevaluasi kesesuaian lahan untuk buah nanas, (3) menetapkan lokasi lahan yang berpotensi untuk pengembangan buah nanas. Metodologi yang digunakan analisis Sistem Informasi Geografi menggunakan software ArcGis 10 dan evaluasi lahan berbasis limiting factor yaitu membandingkan antara karakteristik lahan dengan persyaratan tumbuh tanaman. Hasil penelitian menunjukkan bahwa lahan yang berpotensi untuk pengembangan buah nanas tersebar di bagian selatan Kabupaten Subang. Kecamatan utama yang direkomendasikan untuk pengembangan adalah kecamatan yang memiliki lahan tersedia dan sesuai yang terluas yaitu Kecamatan Cijambe seluas 2.124 ha dan Kecamatan Jalancagak seluas 1.135 ha.
\end{abstract}

Kata kunci: buah nanas, lahan berpotensi, pengembangan

\begin{abstract}
Subang Regency has a main sector in the field of agriculture that is pineapple fruit horticulture. According to Subang Spatial Planning Regulation of 2011 - 2031 agricultural potential that has the opportunity to increase the financing capacity of regional development is pineapple fruit. The objectives of this study were to: (1) delineate the available land for pineapple fruit, (2) evaluate the suitability of the land for pineapple fruit cultivation, (3) determine the potential land location for pineapple fruit development. The methodology used in this study were analysis of Geographic Information System and land evaluation based on limiting factor to compare the characteristics of the land with the requirements of growing plants. The results showed that of potential land for the development of pineapple fruit is spread over the south side of Subang Regency. Sub-district prioritized the recommended for development is sub-district which have the area of available land and have the widest suitability, namely Cijambe Sub-district with an area of 2,124 hectares and Jalancagak sub-district with an area of 1,135 hectares.
\end{abstract}

Keywords: pineapple fruit, potential land, development

\footnotetext{
${ }^{1}$ Program Magister Ilmu Perencanaan Wilayah, Fakultas Pertanian, Institut Pertanian Bogor

${ }^{2}$ Departemen Ilmu Tanah dan Sumberdaya Lahan, Fakultas Pertanian, Institut Pertanian Bogor

${ }^{3}$ Departemen Ilmu Ekonomi, Fakultas Ekonomi dan Manajemen, Institut Pertanian Bogor
} 


\section{PENDAHULUAN}

Indonesia merupakan negara kepulauan yang berbasis pada pengembangan wilayah pada sektor ekstraktif seperti pertanian, perkebunan, perikanan dan peternakan. Kondisi ini ditunjang dengan kenyataan bahwa mayoritas masyarakat Indonesia tinggal di pedesaan dengan mata pencaharian utama di sektor pertanian (Prawoto, 2012). Semakin meningkatnya jumlah penduduk dengan berbagai kebutuhan yang semakin meningkat telah menyebabkan peningkatan kebutuhan lahan, yang berakibat pada ketersediaan sumber daya lahan potensial untuk pengembangan komoditas pertanian yang semakin terbatas (Djaenudin, 2009).

Sektor pertanian merupakan salah satu sektor yang diandalkan, karena sektor pertanian sampai saat ini masih memegang peranan penting dalam menunjang perekonomian nasional. Pertanian merupakan salah satu sektor yang memiliki kontribusi terhadap perekonomian Indonesia. Pembangunan pertanian Indonesia telah dilaksanakan secara bertahap dan berkelanjutan dengan tujuan untuk meningkatkan produksi pertanian agar dapat meningkatkan pendapatan petani dalam mencapai kesejahteraan, peningkatan produksi, peningkatan pendapatan dan kejahteraan petani (Woentina, 2015)

Pembangunan pertanian untuk meningkatkan pendapatan petani, dewasa ini menghadapi permasalahan yang semakin berat. Pertambahan penduduk yang besar, semakin meningkatkan permintaan produk-produk pertanian (1,4-1,6\% setiap tahunnya). Namun di sisi lain, kontribusi produksi sektor pertanian terhadap produksi nasional, dewasa ini cenderung makin menurun. Pertambahan pemukiman dan menciutnya the prime lands lahan-lahan subur untuk berbagai keperluan non-pertanian, cenderung semakin menurunkan luas lahan produktif untuk menghasilkan produk pertanian (Nasrul, 2010).

Hortikultura merupakan salah satu subsektor pada sektor pertanian yang dapat dikembangkan di Indonesia karena dapat meningkatkan pendapatan petani (Soedarya, 2009). Subsektor hortikultura menempati posisi strategis dalam pembangunan sektor pertanian. Kontribusi subsektor hortikultura terhadap pembangunan sektor pertanian dari tahun ke tahun cenderung meningkat yang ditandai dengan peningkatan beberapa indikator makro, seperti produk domestik bruto (PDB), volume ekspor, penyerapan tenaga kerja, dan nilai tukar petani (NTP). Tahun 2015 subsektor hortikultura menyumbang sekitar $18,55 \%$ dari total PDB sektor pertanian. Jumlah tenaga kerja yang terlibat di dalam subsektor hortikultura sekitar 8,4 juta rumah tangga. Jumlah ini meningkat sebesar $76,69 \%$ dibandingkan dengan hasil survei pertanian pada beberapa tahun sebelumnya, yaitu sebesar 4,7 juta rumah tangga. Di bidang produksi hortikultura, penyerapan tenaga kerja meningkat sekitar 5 - $35 \%$ per tahun. Nilai tukar petani (NTP) hortikultura meningkat dari 103,36 pada tahun 2014 menjadi 106,97 pada tahun 2015. Kontribusi ekspor buah-buahan Indonesia ke pasar internasional meningkat menjadi 0,8\% (BPS, 2016).

Hortikultura buah merupakan salah satu sektor andalan di Kabupaten Subang yang memiliki nilai ekonomis cukup tinggi dan sangat potensial baik untuk pasar negeri (domestik) maupun sasaran pasar luar negeri (ekspor) (Rukmana, 2012). Pertanian hortikultura buah di Kabupaten Subang memiliki beberapa jenis komoditas yaitu nanas, pisang, mangga, durian, dan pepaya, namun yang menjadi ciri khas yaitu buah nanas.

Menurut Ditjen PPHP (2016) terdapat produksi tiga komoditas buah andalan ekspor di Indonesia yaitu komoditas buah mangga, nanas, dan manggis. Buah nanas menduduki peringkat kedua buah andalan ekspor di Indonesia dengan jumlah ekspor pada Tahun 2015 mencapai 1.837.159 ton. Dalam hal porsi ekspor terhadap total produksinya, nanas berposisi paling tinggi di antara ketiga komoditas itu dengan porsi $10 \%$ dari total produksi. Kapasitas daya saing nanas yang melebihi manggis dan mangga dapat dipahami sebagai akibat dari pengusahaan dengan standar tinggi oleh perusahaan yang mengintegrasikan 
keseluruhan rantai pasokan secara vertikal disertai dengan usaha budi daya dan pasca panen yang efisien.

Menurut Perda RTRW Kabupaten Subang Tahun 2011 - 2031, buah nanas berpotensi besar dalam peningkatan kemampuan pembiayaan pembangunan wilayah di Kabupaten Subang. Buah nanas di Kabupaten Subang saat ini menjadi ciri khas wilayah, namun produksi dalam beberapa tahun terakhir relative berfluktuasi. Pada tahun 2015 ini produksi tertinggi untuk hortikultura buah di Kabupaten Subang adalah nanas, disusul oleh pisang dan durian. Hasil produksi nanas pada tahun 2015 mencapai 136.567 ton dengan sentra produksi terdapat di Kecamatan Jalancagak, Ciater dan Cijambe (sekitar 90 \% dari total produksi nanas Kabupaten Subang). Produksi pisang di tahun 2015 mencapai 101.455 ton sementara produksi buah durian mencapai 18.230 ton (BPS, 2016).

Produksi dan luas panen hortikultura buah nanas di Kabupaten Subang dalam beberapa tahun terakhir ini mengalami penurunan yang signifikan. Untuk itu perlu dilihat kembali beberapa hal, antara lain dukungan kesesuaian lahan untuk pengembangannya. Tujuannya adalah agar buah nanas dapat terus berkembang dan layak untuk diusahakan, agar kontribusinya bagi pengembangan wilayah Kabupaten Subang dapat lebih dioptimalkan.

Penelitian ini bertujuan untuk : 1) mendelineasi lahan tersedia untuk buah nanas di Kabupaten Subang, 2) mengevaluasi kesesuaian lahan untuk buah nanas di Kabupaten Subang, dan 3) menetapkan lokasi lahan yang berpotensi untuk pengembangan buah nanas di Kabupaten Subang

\section{METODE PENELITIAN}

Penelitian ini dilaksanakan di Kabupaten Subang, Provinsi Jawa Barat. Kabupaten ini memiliki 30 kecamatan yang terdiri dari 245 desa dan 8 kelurahan. Penelitian dilakukan pada bulan Agustus 2016 sampai September 2017. Data yang digunakan dalam penelitian ini berupa data sekunder dan data primer. Data sekunder dikumpulkan dari berbagai instansi sesuai dengan substansi yang akan dikaji, yaitu dari Bappeda Kabupaten Subang, BPS Kabupaten Subang, Dinas Pertanian Tanaman Pangan dan Hortikultura Kabupaten Subang, dan BPN Kabupaten Subang. Data primer diperoleh dari cek lapang berupa identifikasi karakteristik lahan dan wawancara kepada petani dan masyarakat. Hubungan tujuan penelitian, jenis data, sumber data, dan teknis analisis disajikan pada Tabel 1.

Tabel 1. Tujuan, Jenis Data, Sumber Data, dan Teknik Analisis Data

\begin{tabular}{|c|c|c|c|c|}
\hline Tujuan & Jenis Data & Sumber Data & $\begin{array}{c}\text { Teknik } \\
\text { Analisis } \\
\text { Data } \\
\end{array}$ & Output \\
\hline $\begin{array}{l}\text { Mendelineasi lahan } \\
\text { tersedia untuk buah } \\
\text { nanas di Kabupaten } \\
\text { Subang }\end{array}$ & $\begin{array}{l}\text { - Peta Pola Ruang Kabupaten } \\
\text { Subang Tahun } 2011 \text { - } 2031 \\
\text { - Peta Kawasan Hutan Tahun } \\
2015 \\
\text { - Peta Penggunaan Lahan } \\
\text { Tahun } 2015\end{array}$ & $\begin{array}{l}\text {-Bappeda Kabupaten } \\
\text { Subang } \\
\text {-Penelitian } \\
\text { Widiatmaka et al. } \\
\text { (2016) }\end{array}$ & Overlay & $\begin{array}{l}\text { Peta } \\
\text { ketersediaan } \\
\text { lahan }\end{array}$ \\
\hline $\begin{array}{l}\text { Mengevaluasi } \\
\text { kesesuaian lahan } \\
\text { untuk buah nanas di } \\
\text { Kabupaten Subang }\end{array}$ & $\begin{array}{l}\text { - Peta ketersediaan lahan } \\
\text { - Satuan peta tanah, peta } \\
\text { curah hujan, peta lereng, dan } \\
\text { peta suhu } \\
\text { - Karakteristik tanah, drainase, } \\
\text { tekstur, kedalaman efektif, } \\
\text { pH, kandungan unsur kimia }\end{array}$ & $\begin{array}{l}\text { - Output tujuan } 1 \\
\text { - Bappeda Kabupaten } \\
\text { Subang } \\
\text { - Penelitian } \\
\text { Widiatmaka et al. } \\
(2016)\end{array}$ & $\begin{array}{l}\text { Limiting } \\
\text { Factor }\end{array}$ & $\begin{array}{l}\text { Peta } \\
\text { kesesuaian } \\
\text { lahan }\end{array}$ \\
\hline $\begin{array}{l}\text { Menentukan lokasi } \\
\text { lahan yang }\end{array}$ & $\begin{array}{l}\text { - Peta administrasi } \\
\text { Kabupaten Subang }\end{array}$ & $\begin{array}{l}\text {-Bappeda Kabupaten } \\
\text { Subang }\end{array}$ & Overlay & $\begin{array}{l}\text { Potensi lahan } \\
\text { pengembangan }\end{array}$ \\
\hline
\end{tabular}




\begin{tabular}{|c|c|c|c|c|}
\hline Tujuan & Jenis Data & Sumber Data & $\begin{array}{c}\text { Teknik } \\
\text { Analisis } \\
\text { Data }\end{array}$ & Output \\
\hline $\begin{array}{l}\text { berpotensi untuk } \\
\text { pengembangan buah } \\
\text { nanas di Kabupaten } \\
\text { Subang }\end{array}$ & $\begin{array}{l}\text { - Peta kesesuaian lahan } \\
\text { - Data produksi dan luas } \\
\text { panen buah nanas (sebagai } \\
\text { kriteria penentuan lokasi } \\
\text { lahan berpotensi) }\end{array}$ & $\begin{array}{l}\text { - Output tujuan } 2 \\
\text {-BPS dan Dinas } \\
\text { Pertanian Tanaman } \\
\text { Pangan Kabupaten } \\
\text { Subang }\end{array}$ & & $\begin{array}{l}\text { hortikultura } \\
\text { komoditas } \\
\text { buah nanas di } \\
\text { Kabupaten } \\
\text { Subang }\end{array}$ \\
\hline
\end{tabular}

\section{Delineasi Lahan Tersedia}

Zonasi komoditas merupakan pedoman bagi para perencana untuk memilih lokasi lahan untuk pengembangan komoditas tertentu sesuai dengan potensinya (Mubekti et al. 2006). Analisis ketersediaan lahan dilakukan pada tahap awal untuk pemilihan wilayah yang akan dijadikan sebagai wilayah pengembangan (Widiatmaka, 2013). Analisis ketersediaan lahan dilakukan dengan mengintegrasikan data produksi dan luas pertanian hortikultura buah dan peta sebaran pertanian hortikultura buah, peta ijin lokasi, peta RTRW, peta kawasan hutan, dan peta penggunaan lahan (Widiatmaka et al. 2016) dengan cara overlay dengan menggunakan software ArcGis 10.

\section{Evaluasi Kesesuaian Lahan}

Analisis kesesuaian lahan untuk komoditas buah dilakukan dengan teknik limiting factor, yaitu membandingkan antara karakteristik lahan dengan persyaratan tumbuh tanaman (Hardjowigeno dan Widiatmaka, 2007). Karakteristik lahan yang digunakan adalah karakteristik lahan pada setiap Satuan Peta Tanah (SPT), meliputi curah hujan, lereng, dan suhu, drainase, tekstur, kedalaman efektif, $\mathrm{pH}$, dan kandungan $\mathrm{N}, \mathrm{P}, \mathrm{K}, \mathrm{Ca}$ dapat dipertukarkan. Data-data tersebut bersumber dari penelitian sebelumnya (Widiatmaka et al. 2016).

\section{Penentuan Lokasi Lahan Berpotensi}

Data hasil evaluasi lahan yang dilengkapi dengan data penggunaan dan status lahan dapat digunakan sebagai dasar dalam menyusun arahan pengembangan komoditas (Djaenudin, 2006). Setelah dihasilkan peta letersediaan lahan dan kesesuaian lahan, maka dapat dihasilkan data atribut kelas kesesuaian lahan untuk buah nanas berupa luasan yang sesuai menurut per Kecamatan dengan dilakukan overlay dengan peta administrasi, sehingga duhasilkan data sebaran kelas kesesuian lahan menurut per kecamatan. Lokasi yang dipilih sebagai lokasi potensi lahan untuk pengembangan buah nanas yaitu dengan kriteria bahwa luas lahan yang sesuai memiliki luasan yang paling luas dan paling sesuai yaitu dengan kelas S3 dan S2.

\section{HASIL DAN PEMBAHASAN}

\section{Lahan tersedia untuk buah nanas di Kabupaten Subang}

\section{Penggunaan Lahan Kabupaten Subang}

Berdasarkan hasil analisis Widiatmaka et al (2016), penggunaan lahan tahun 2015 di Kabupaten Subang diidentifikasi sebanyak 8 (delapan) kelas penggunaan lahan. Penggunaan lahan yang dikategorikan tersedia yaitu ladang/tegalan dan semak belukar, sedangkan untuk penggunaan lahan yang lain dikategorikan tidak tersedia. Penggunaan lahan Kabupaten Subang secara terperinci disajikan pada Tabel 1 dan Gambar 1. 
Tabel 1. Penggunaan lahan Kabupaten Subang

\begin{tabular}{lr}
\hline \multicolumn{1}{c}{ Penggunaan Lahan } & Luas (ha) \\
\hline Hutan & 18.620 \\
Ladang/Tegalan & 6.954 \\
Perkebunan & 51.892 \\
Permukiman & 16.229 \\
Sawah & 112.428 \\
Semak Belukar & 64 \\
Sungai/Danau/Waduk/Situ & 779 \\
Tambak & 8.928 \\
& Jumlah \\
\hline
\end{tabular}

Sumber : Widiatmaka et al. (2016)

Luas penggunaan lahan yang paling luas adalah sawah dengan luasan sebesar 112.428 ha. luas penggunaan lahan terkecil adalah semak belukar dengan luasan 63,99 ha. Luas lahan tersedia dari penggunaan lahan yaitu dengan jumlah 7.017 ha dengan rincian penggunaan lahan ladang/tegalan dengan luas 6.954 ha dan penggunaan lahan semak belukar dengan luas 64 ha.

\section{Kawasan Hutan Kabupaten Subang}

Lahan yang dikategorikan tidak tersedia untuk pengembangan komoditas pada peta kawasan hutan adalah lahan yang berada dalam cagar alam, hutan lindung, hutan produksi terbatas, hutan produksi, hutan cadangan, hutan pangonan, taman buru, taman wisata alam, dan taman hutan rakyat. Lahan yang berada di areal penggunaan lain (APL) dikategorikan lahan tersedia.

Kawasan hutan yang terdapat di Kabupaten Subang memiliki 5 fungsi kawasan yaitu area penggunaan lain (APL), hutan lindung (HL), hutan produksi (HP), hutan produksi terbatas (HPT), dan hutan suakan alam dan wisata (HSA-W). Lahan tersedia di Kabupaten Subang yaitu lahan yang berada di areal penggunaan lain (APL). Kawasan hutan Kabupaten Subang secara terperinci disajikan pada Tabel 2 dan Gambar 1.

Tabel 2. Fungsi kawasan hutan Kabupaten Subang

\begin{tabular}{lr}
\hline \multicolumn{1}{c}{ Fungsi Kawasan Hutan } & Luas (ha) \\
\hline Area Penggunaan Lain (APL) & 185.435 \\
Hutan Lindung (HL) & 7.255 \\
Hutan Produksi (HP) & 17.846 \\
Hutan Produksi Terbatas (HPT) & 3.108 \\
Hutan Suaka Alam dan Wisata (HSA-W) & 1.577 \\
$\quad$ Jumlah & 215.221 \\
\hline
\end{tabular}

Sumber : Bappeda Kabupaten Subang (2016)

Luas kawasan hutan yang paling luas adalah areal penggunaan lain dengan luasan sebesar 185.435 ha. luas kawasan hutan terkecil adalah hutan suaka alam dan wisata dengan luasan 1.577 ha. Kawasan yang tersedia untuk pada peta kawasan hutan ini adalah areal penggunaan lain (APL) seluas 185.435 ha. 


\section{Pola Ruang (RTRW) Kabupaten Subang}

Lahan yang dikategorikan tidak tersedia pada peta pola ruang (RTRW) adalah lahan yang berada dalam kawasan hutan bakau, hutan lindung, hutan produksi, kampung, kebun/perkebunan, perikanan, permukiman, tani lahan basah, dan zona industri. Lahan yang dikategorikan kepada lahan tersedia yaitu lahan yang berada dalam kawasan budidaya. Pola ruang Kabupaten Subang secara terperinci disajikan pada Tabel 3 dan Gambar 1.

Tabel 3. Fungsi kawasan pada peta pola ruang (RTRW) Kabupaten Subang

\begin{tabular}{lr}
\hline \multicolumn{1}{c}{ Fungsi Kawasan } & Luas (ha) \\
\hline Hutan Bakau & 10.114 \\
Hutan Lindung & 10.711 \\
Hutan Produksi & 10.271 \\
Kampung & 274 \\
Kebun Campuran & 31.869 \\
Kebun/Perkebunan & 14.225 \\
Perikanan & 747 \\
Permukiman & 18.419 \\
Tani Lahan Basah & 109.473 \\
Zona Industri & 11.620 \\
& Jumlah \\
\hline
\end{tabular}

Sumber : Bappeda Kabupaten Subang (2016)

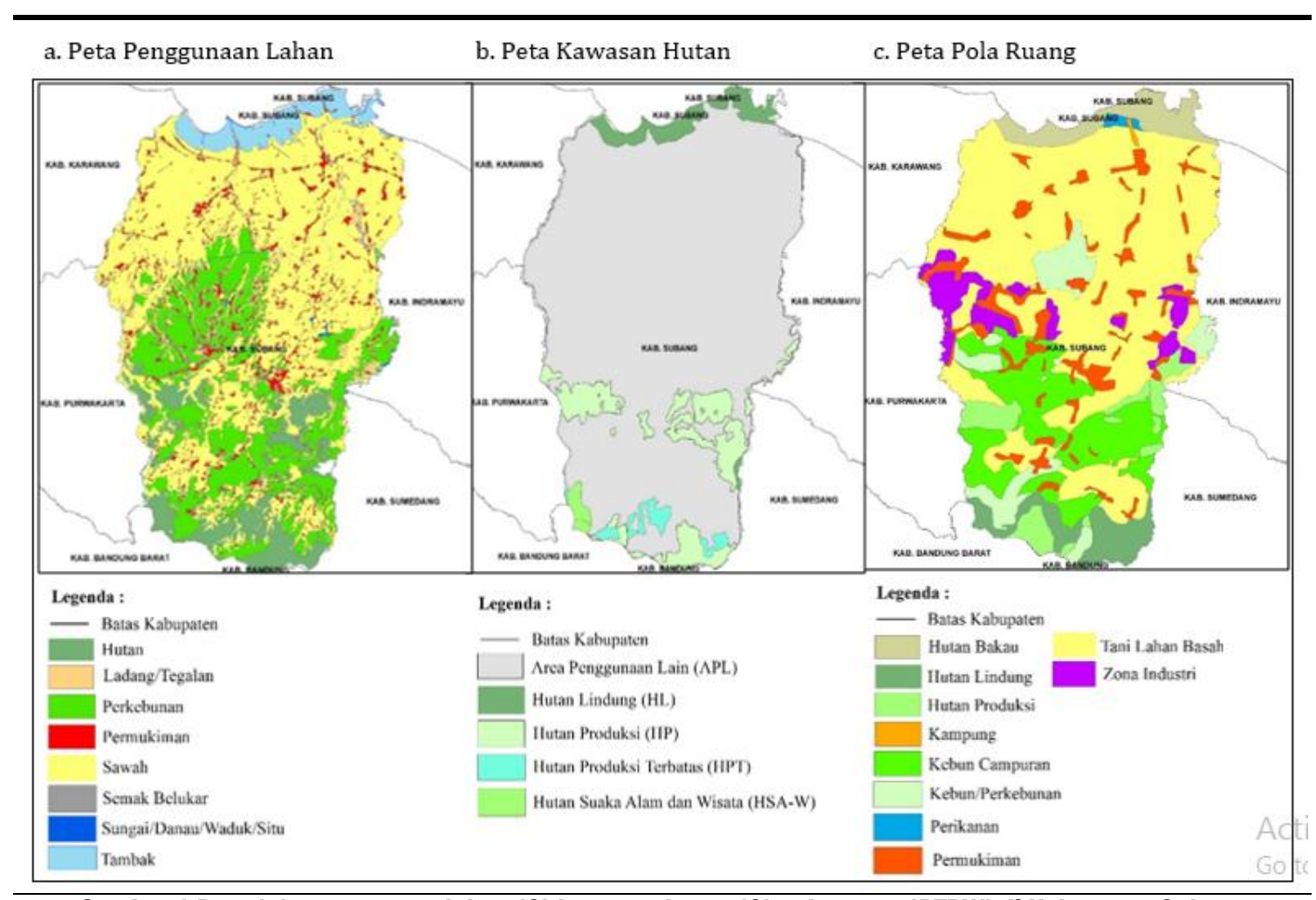

Gambar 1 Peta (a) penggunaan lahan (2) kawasan hutan (3) pola ruang (RTRW) di Kabupaten Subang 
Luas lahan yang paling luas adalah tani lahan basah dengan luasan sebesar 109.473 ha. luas lahan terkecil adalah kampung dengan luasan 274 ha. Penggunaan lahan yang dikategorikan lahan tersedia khususnya untuk buah nanas adalah lahan kebun campuran dengan luas 31.869 ha.

Lahan tersedia yang dapat digunakan sebagai pengembangan lahan komoditas buah nanas di Kabupaten Subang merupakan lokasi yang diperuntukkan untuk kawasan kebun campuran, areal penggunaan lain, tegalan/ladang, belukar/semak, dan rumput/tanah kosong. Ketersediaan lahan merupakan penggunaan lahan yang dapat dialokasikan untuk penggunaan lain secara umum. Hasil analisis ketersediaan lahan untuk tanaman komoditas buah nanas yaitu seluas 6.285 ha. Lahan yang tersedia inilah yang nantinya akan dievaluasi kesesuaian lahan terhadap komoditas buah nanas di masing-masing Kecamatan. Lahan tersedia di Kabupaten Subang secara terperinci disajikan pada Tabel 4 dan Gambar 2.

Tabel 4. Lahan tersedia untuk komoditas buah nanas di Kabupaten Subang

\begin{tabular}{clll}
\hline Pola Ruang & \multicolumn{1}{c}{ Kawasan Hutan } & Penggunaan Lahan & Luas (Ha) \\
\hline Kebun Campuran & Area Penggunaan Lain (APL) & Belukar/Semak & 556 \\
Kebun Campuran & Area Penggunaan Lain (APL) & Rumput/Tanah kosong & 21 \\
Kebun Campuran & Area Penggunaan Lain (APL) & Tegalan/Ladang & 5.708 \\
\hline & Jumlah & & 6.285 \\
\hline
\end{tabular}

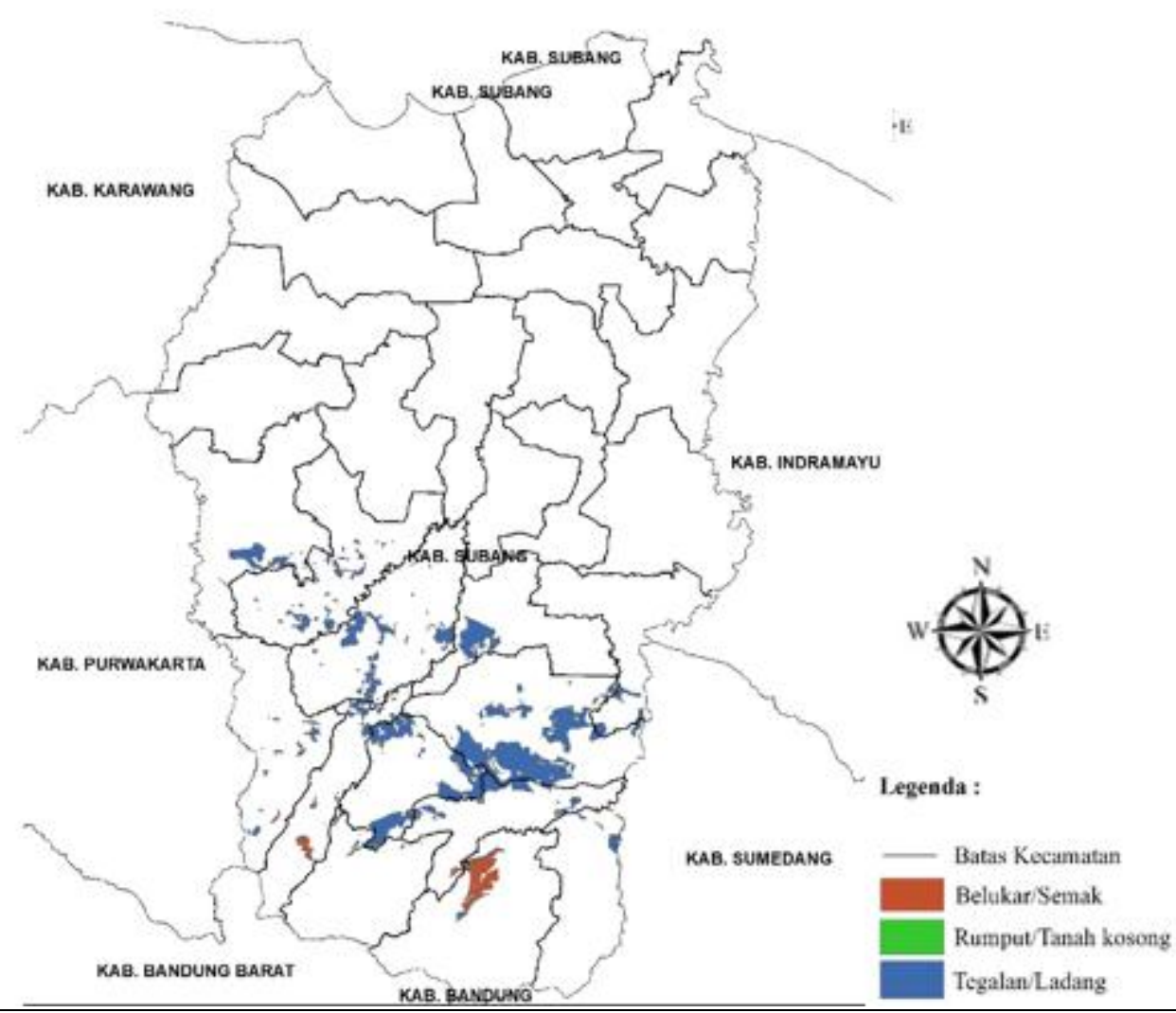

Gambar 2 Peta ketersediaan lahan untuk komoditas buah nanas di Kabupaten Subang

\section{Kesesuaian lahan untuk buah nanas di Kabupaten Subang}

Evaluasi kesesuaian lahan dilakukan dengan evaluasi lahan berbasis limiting factor yaitu membandingkan antara karakteristik lahan dengan persyaratan tumbuh tanaman buah nanas namun dengan data yang tersedia saja (tidak semua kriteria digunakan). Data 
yang tersedia yaitu 15 kriteria dan syarat tumbuh tanaman untuk buah nanas (BBSDLP, 2011). Syarat tumbuh tanaman buah nanas disajikan pada Tabel 5.

Tabel 5 Syarat tumbuh tanaman buah nanas yang digunakan

\begin{tabular}{|c|c|c|c|c|}
\hline \multirow{2}{*}{$\begin{array}{l}\text { Persyaratan penggunaan/ } \\
\text { karakteristik lahan }\end{array}$} & \multicolumn{4}{|c|}{ Kelas kesesuaian Lahan } \\
\hline & S1 & S2 & S3 & $\mathbf{N}$ \\
\hline \multicolumn{5}{|l|}{ Temperatur (tc) } \\
\hline Temperatur rerata $\left({ }^{\circ} \mathrm{C}\right)$ & $20-26$ & $\begin{array}{l}26-30 \\
18-20\end{array}$ & $\begin{array}{l}30-35 \\
16-18\end{array}$ & $\begin{array}{l}>35 \\
<16\end{array}$ \\
\hline \multicolumn{5}{|l|}{ Ketersediaan air (wa) } \\
\hline Curah hujan (mm) & $1.000-1.600$ & $\begin{array}{l}800-1.000 \\
1.600-2.000\end{array}$ & $\begin{array}{l}600-800 \\
>2.000\end{array}$ & $<600$ \\
\hline \multicolumn{5}{|l|}{ Ketersediaan oksigen (oa) } \\
\hline Drainase & Baik, sedang & Agak terhambat & $\begin{array}{l}\text { Terhambat, } \\
\text { agak cepat }\end{array}$ & $\begin{array}{l}\text { Sangat } \\
\text { terhambat, } \\
\text { cepat }\end{array}$ \\
\hline \multicolumn{5}{|l|}{ Media perakaran (rc) } \\
\hline Tekstur & $\begin{array}{l}\text { Halus, agak } \\
\text { halus, sedang }\end{array}$ & Agak kasar & Sangat halus & Kasar \\
\hline Kedalaman tanah $(\mathrm{cm})$ & $>60$ & $40-60$ & $20-40$ & $<20$ \\
\hline \multicolumn{5}{|l|}{ Retensi hara (nr) } \\
\hline KTK tanah (cmol) & $>16$ & $5-16$ & $<5$ & \\
\hline \multirow[t]{2}{*}{$\mathrm{pH} \mathrm{H} \mathrm{H}_{2} \mathrm{O}$} & $5,0-6,5$ & $4,3-5,0$ & $<4,3$ & \\
\hline & & $6,5-7,0$ & $<7,0$ & \\
\hline C-organik (\%) & $>1,2$ & $0,8-1,2$ & $<0,8$ & \\
\hline \multicolumn{5}{|l|}{ Hara tersedia (na) } \\
\hline $\mathrm{N}$ total $(\%)$ & Sedang & Rendah & $\begin{array}{l}\text { Sangat } \\
\text { rendah }\end{array}$ & - \\
\hline $\mathrm{P} 2 \mathrm{O} 5$ (mg/100 g) & Sedang & Rendah & $\begin{array}{l}\text { Sangat } \\
\text { rendah }\end{array}$ & - \\
\hline $\mathrm{K} 2 \mathrm{O}(\mathrm{mg} / 100 \mathrm{~g})$ & Sedang & Rendah & $\begin{array}{l}\text { Sangat } \\
\text { rendah }\end{array}$ & - \\
\hline \multicolumn{5}{|l|}{ Bahaya erosi (eh) } \\
\hline Lereng $(\%)$ & $<8$ & $8-15$ & $15-30$ & $>30$ \\
\hline Bahaya erosi & Sangat ringan & Ringan - sedang & Berat & Sangat berat \\
\hline \multicolumn{5}{|l|}{ Penyiapan lahan (lp) } \\
\hline Batuan di permukaan (\%) & $<5$ & $5-15$ & $15-40$ & $>40$ \\
\hline
\end{tabular}

Sumber : BBSDLP, 2011

Peta kesesuaian lahan untuk komoditas buah nanas yang dikategorikan ke dalam beberapa kelas kesesuaian lahan dilakukan teknik limiting factor dengan syarat tumbuh tanaman buah nanas. Hasil analisis kesesuaian lahan dapat dilihat secara spasial di Gambar 3 dan disajikan terperinci pada Tabel 6 .

Tabel 6 Kesesuaian lahan untuk komoditas buah nanas di Kabupaten Subang

\begin{tabular}{|c|c|c|c|}
\hline $\begin{array}{c}\text { Kelas } \\
\text { kesesuaian lahan }\end{array}$ & Unit lahan & $\begin{array}{l}\text { Luas } \\
\text { ha }\end{array}$ & $\%$ \\
\hline $\mathrm{N}$ & 10,13 & 283 & 4,5 \\
\hline S3 & $\begin{array}{l}1,3,7,8,9,11 \\
12,14,15,16,17,18 \\
19,20,21,22,23,24 \\
25,26\end{array}$ & 5.903 & 93,9 \\
\hline S2 & $2,4,5,6$ & 99 & 1,6 \\
\hline \multicolumn{2}{|c|}{ Jumlah } & 6.285 & 100 \\
\hline
\end{tabular}




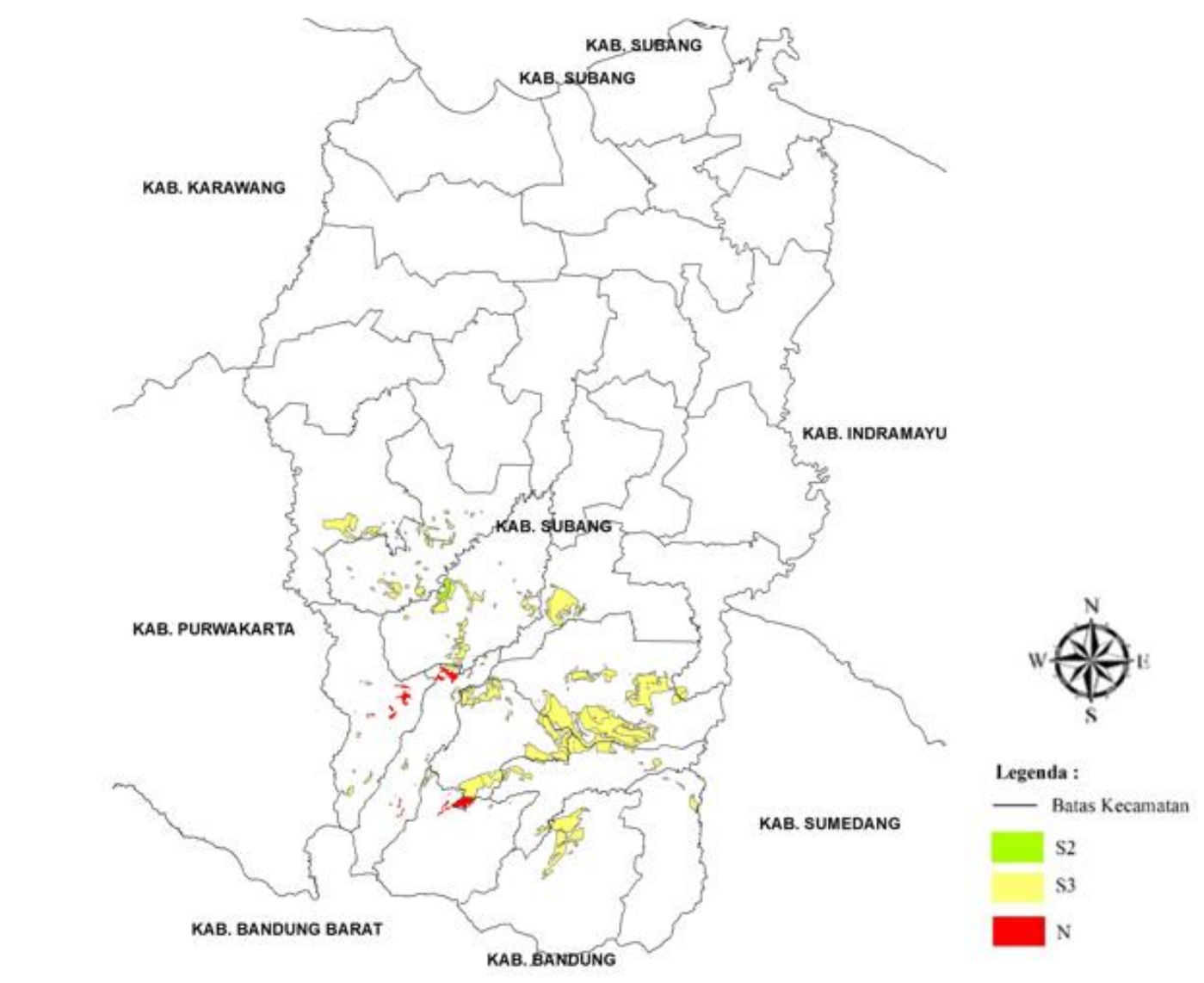

Gambar 3 Peta kesesuaian lahan untuk komoditas buah nanas di Kabupaten Subang

Berdasarkan hasil analisis, diperoleh beberapa kelas kesesuaian lahan aktual untuk buah nanas di Kabupaten Subang, yaitu:

- Kelas kesesuaian lahan S2 seluas 99 ha atau 1,6\% dari jumlah keseluruhan luas lahan tersedia;

- Kelas kesesuaian lahan S3 seluas 5.903 ha atau 93,9\% dari jumlah keseluruhan luas lahan tersedia;

- Kelas kesesuaian lahan $\mathrm{N}$ seluas 283 ha atau 4,5\% dari jumlah keseluruhan luas lahan tersedia;

Faktor pembatas kelas kesesuaian lahan yang sangat berpengaruh terhadap kesesuaian lahan untuk buah nanas ini adalah temperatur, ketersediaan air, media perakaran, retensi hara, ketersediaan hara, dan bahaya erosi. Upaya penanganan yang dapat dilakukan untuk mengatasi faktor penghambat tersebut yaitu :

- Usaha pengurangan laju erosi, pembuatan teras, penanaman sejajar kontur,penanaman tanaman penutup tanah

- Irigasi

- Pengapuran atau penambahan bahan organik

- Perbaikan sistem drainase seperti pembuatan saluran drainase

- Pemupukan 
Menentukan lokasi lahan yang berpotensi untuk pengembangan buah nanas di Kabupaten Subang

Lokasi lahan yang berpotensi dengan melihat dari lahan tersedia dan kesesuaian lahan dengan dilakukan pengalokasian dengan menggabungkan tabulasi data overlay dengan peta administrasi, sehingga terlihat alokasi lahan pada setiap kecamatan yang sesuai dan tersedia. Untuk lebih jelas mengenai alokasi lahan untuk pengembangan hortikultura buah nanas di Kabupaten Subang disajikan pada Tabel 7.

Tabel 7 Alokasi lahan pengembangan hortikultura buah nanas di Kabupaten Subang

\begin{tabular}{|c|c|c|c|c|}
\hline Kecamatan & $\mathbf{N}$ & S2 & S3 & Jumlah (Ha) \\
\hline Kec.Ciater & 27,40 & & 40,90 & 68 \\
\hline Kec.Cibogo & & 0,30 & 63,50 & 64 \\
\hline Kec.Cijambe & 1,05 & & $2.122,97$ & 2.124 \\
\hline Kec.Cipeundey & & & 309,11 & 309 \\
\hline Kec.Cisalak & & & 509,82 & 510 \\
\hline Kec.Dawuan & & 94 & 480,66 & 549 \\
\hline Kec.Jalancagak & 76,70 & 15,03 & $1.042,17$ & 1.135 \\
\hline Kec.Kalijati & & & 326,87 & 327 \\
\hline Kec.Kasomalang & & & 413,41 & 413 \\
\hline Kec.Sagalaherang & 92,82 & 0,23 & 86,46 & 179 \\
\hline Kec.Serangpanjang & 85,02 & & 63,50 & 148 \\
\hline Kec.Subang & & 15,22 & 388,06 & 403 \\
\hline Kec.Tanjungsiang & & & 55,85 & 56 \\
\hline Jumlah & 282,98 & 98,72 & $5.903,28$ & 6.285 \\
\hline
\end{tabular}

Secara umum lahan yang sesuai di Kabupaten Subang tersebar di bagian selatan yaitu Kecamatan Cipeundeuy, Kecamatan Kalijati, Kecamatan Dawuan, Kecamatan Subang, Kecamatan Jalancagak, Kecamatan Cijambe, Kecamatan Kasomalang, Kecamatan Serangpanjang, Kecamatan Sagalaherang, Kecamatan Ciater, Kecamatan Kasomalang, Kecamatan Cisalak, Kecamatan Tanjungsiang.

Kecamatan utama yang direkomendasikan untuk pengembangan adalah kecamatan yang memiliki lahan tersedia dan sesuai yang terluas yaitu Kecamatan Cijambe seluas 2.124 ha dan Kecamatan Jalancagak seluas 1.134 ha.

\section{KESIMPULAN}

Lahan tersedia yang dapat digunakan sebagai pengembangan lahan komoditas buah nanas di Kabupaten Subang merupakan lokasi yang diperuntukkan untuk kawasan kebun campuran, areal penggunaan lain, tegalan/ladang, belukar/semak, dan rumput/tanah kosong dengan luas lahan tersedia seluas 6.285 ha.

Kesesuaian lahan buah nanas di Kabupaten Subang memiliki luas 6.285 ha. Terdapat 3 kelas kesesuaian lahan yaitu kelas N seluas 283 Ha, kelas S3 seluas 5.903 ha, dan kelas S2 seluas 99 ha.

Lahan yang berpotensi untuk pengembangan buah nanas tersebar di bagian selatan Kabupaten Subang yaitu Kecamatan Cipeundeuy, Kecamatan Kalijati, Kecamatan Dawuan, Kecamatan Subang, Kecamatan Jalancagak, Kecamatan Cijambe, Kecamatan Kasomalang, Kecamatan Serangpanjang, Kecamatan Sagalaherang, Kecamatan Ciater, Kecamatan Kasomalang, Kecamatan Cisalak, Kecamatan Tanjungsiang. Kecamatan utama yang 
direkomendasikan untuk pengembangan adalah kecamatan yang memiliki lahan tersedia dan sesuai yang terluas yaitu Kecamatan Cijambe seluas 2.124 ha dan Kecamatan Jalancagak seluas 1.134 ha.

\section{DAFTAR PUSTAKA}

[Bappeda] Badan Perencanaan Pembangunan Daerah Kabupaten Subang. 2016. Rencana Tata Ruang Wilayah Kabupaten Subang Tahun 2011 - 2031. Subang (ID) : Bappeda Kabupaten Subang.

[BBSDLP] Balai Besar Penelitian dan Pengembangan Sumberdaya Lahan Pertanian. 2011. Petunjuk Teknis Evaluasi Lahan untuk Komoditas Pertanian. Bogor (ID) : Balai Besar Penelitian dan Pengembangan Sumberdaya Lahan Pertanian

[BPS] Badan Pusat Statistik Kabupaten Subang. 2016. Kabupaten Subang Dalam Angka 2016. Subang (ID) : Badan Pusat Statistik Kabupaten Subang

[BPS] Badan Pusat Statistik Provinsi Jawa Barat. 2016. Provinsi Jawa Barat Dalam Angka 2015. Bandung (ID) : Badan Pusat Statistik Provinsi Jawa Barat

[Ditjen PPHP]. Direktorat Jenderal Pengolahan dan Pemasaran Hasil Pertanian. 2016. Produksi, ekspor, impor dan neraca produk hortikultura 2014-2015. Jakarta (ID) : Dirjen PPHP

Djaenudin D, Hendrisman, Zaini. 2006. Penelitian kesesuaian lahan tanaman pangan dan perkebunan : Studi kasus di daerah Tanjungbintang, Provinsi Lampung. Jurnal Tanah Tropika .12(1) : 61-68

Djaenudin D. 2009. Prospek Penelitian Potensi Sumber Daya Lahan di Wilayah Indonesia. Jurnal Pengembangan Inovasi Pertanian. 2(4) : 243-257

Hardjowigeno S, Widiatmaka. 2007. Evaluasi Kesesuaian Lahan dan Perencanaan Tataguna Lahan. Yogyakarta (ID) : Gajah Mada University Press

Mubekti, Rahmadi A, Ritung S. 2006. Teknologi Remote Sensing Dan Gis Untuk Zonasi Komoditas Dan Ketersediaan Sumberdaya Lahan (Studi Kasus: Kabupaten Agam, Sumbar). Jurnal Sains dan Teknologi Indonesia. 8(3) : 124-132

Nasrul B. 2010. Penyebaran Dan Potensi Lahan Gambut di Kabupaten Bengkalis untuk Pengembangan Pertanian. Jurnal Agroteknologi. 1(1) : $1-7$

Prawoto N. 2012. Model Pengembangan Dan Pemberdayaan Masyarakat Berbasis Kemandirian Untuk Mewujudkan Ketahanan Ekonomi Dan Ketahanan Pangan (Strategi Pemberdayaan Ekonomi Pada Masyarakat Dieng Di Propinsi Jawa Tengah). Jurnal Organisasi dan Manajemen. 8(2) : 135-154

Rukmana. 2012. Strategi Pengembangan Pemasaran : Studi Kasus Kabupaten di Indonesia. Jakarta (ID) : Universitas Indonesia Press (Ul-Press)

Widiatmaka. 2013. Analisis Sumberdaya Wilayah untuk Perencanaan Tataguna Lahan. Bogor (ID) : Institut Pertanian Bogor.

Widiatmaka, Ambarwulan W, Santoso P, Sabiham S, Machfud, Hikmat M. 2016. Remote sensing and land suitability analysis to establish local specific inputs for paddy fields in Subang, West Java. Environmental Sciences. 33 (2016) : $94-107$

Woentina K. 2015. Analisis Kelayakan Usahatani Nanas Di Desa Doda Kecamatan Kinovaro Kabupaten Sigi. eJ Agrotekbis. 3 (2) : $240-246$ 